\title{
Occupant behaviour and thermal comfort in buildings: Monitoring the end user
}

\author{
Loes Visser ${ }^{1,2, *}$, Boris Kingma ${ }^{3,4}$, Eric Willems ${ }^{2}$, Wendy Broers $^{5}$, Marcel Loomans ${ }^{1}$, Henk Schellen ${ }^{1}$, \\ Peter op 't Veld ${ }^{2}$, Wouter van Marken Lichtenbelt ${ }^{3}$ \\ ${ }^{1}$ Department of the Built Environment, Unit Building Physics and Services, Eindhoven University of Technology, The Netherlands, \\ ${ }^{2}$ Huygen Engineers \& Consultants B.V., Maastricht, The Netherlands \\ ${ }^{3}$ Maastricht University Medical Center+, Department of Human Biology, NUTRIM School for Nutrition, Toxicology and Metabolism, \\ Maastricht, The Netherlands, \\ ${ }^{4}$ The Netherlands Organisation for Applied Scientific Research, Unit Defense, Safety and Security, Dep. of Training \& Performance \\ Innovations, Soesterberg, The Netherlands \\ ${ }^{5}$ Zuyd University of Applied Sciences, Heerlen, The Netherlands
}

\begin{abstract}
Studies indicate that the energy performance gap between real and calculated energy use can be explained for $80 \%$ by occupant behaviour. This human factor may be composed of routine and thermoregulatory behaviour. When occupants do not feel comfortable due to high or low operative temperatures and resulting high or low skin temperatures, they are likely to exhibit thermoregulatory behaviour. The aim of this study is to monitor and understand this thermoregulatory behaviour of the occupant. This is a detailed study of two females living in a rowhouse in the city of Heerlen (Netherlands). During a monitoring period of three weeks over a time span of three months the following parameters were monitored: activity level, clothing, micro climate, skin temperatures and thermal comfort and sensation. Their micro climate was measured at five positions on the body to assess exposed near body conditions and skin temperature. Every two hours they filled in a questionnaire regarding their thermal comfort and sensation level (7-point scale), clothing, activities and thermoregulatory behaviour. The most comfortable (optimal) temperature was calculated for each person by adopting a biophysical model, a thermoneutral zone model. This study shows unique indivual comfort patterns in relation to ambient conditions. An example is given how this information can be used to calculate the buildings energy comsumption.
\end{abstract}

\section{Introduction}

Studies indicate that the human factor is responsible for $80 \%$ of the performance gap between calculated and realized energy use [1]. Over the last couple of years, it has become easier to calculate building related energy performance with simulation programs. However, these calculations are focussed on energy use of buildings, based on fixed user behaviour conditions and reference climate years. Therefore, these calculations lack information about real life performances. In this way an energy performance gap is inevitable and a result of this gap are strong deviations in energy use between almost similar apartments [2].This is caused by "the human factor" with daily routines and thermoregulatory behaviour as most important parameters [1]. Examples of thermoregulatory behaviour are moving from one room to another, changing clothes and adjusting the thermostat. These actions are taken to increase comfort levels [3].

Previous research of Fanger [4] indicated that there are a number of parameters that contribute to the thermal environment, such as air temperature, mean radiant temperature, relative air velocity, vapor pressure in ambient air, the human activity level and the clothing worn. This is called the PMV-model and is based on the predicted mean vote (PMV) of the general population. Several studies show a good agreement between the PMV and the actual mean vote, this is particularly found for uniform and steady-state environments [5,6]. Other studies found differences between the PMV and the actual mean vote due to differences in subpopulations (e.g. males versus females, lean versus obese, elderly and young) [7]. In this study an adapted version of the thermoneutral zone (TNZ) model is used which describes thermal comfort in relation to environmental and skin temperature and is a more individual approach to investigate comfort $[8,9]$. This model may be more suitable to clarify the variation in heating demand between similar dwellings by means of differences in thermoregulatory behaviour of occupants. The area in which people feel neutral in their environment is called the TNZ, wherein the comfort zone acts as centre. The TNZ is defined as 'the range of ambient temperature at which temperature regulation is achieved only by control

\footnotetext{
* Corresponding author: 1.visser@huygen.net
} 
of sensible (dry) heat loss, i.e. without regulatory changes in metabolic heat production or evaporative heat loss' [10]. This definition only includes physiological mechanisms of the body, e.g. changing the skin temperature to maintain the body's core temperature, and does not include the individual thermoregulatory behaviour of people. ASHRAE [11] concluded that for people thermal behaviour is for people a major factor to come to satisfaction with their thermal environment. The thermoregulatory behaviour will therefore probably occur when occupants experience discomfort.

Previous research has focused only on experiments in laboratories or artificial environments designed to reflect the real living or working space. No experiments have been conducted with test-subjects in their own home or working space. This lack is caused by the difficulty to control all the physical parameters in a dwelling (e.g. temperature, relative humidity, ventilation, air velocity, $\mathrm{CO}_{2}$ concentration). Therefore, during this study the testsubjects were living in a fully monitored dwelling where they were closely observed and monitored to obtain insight in their individual thermoregulatory behaviour. The aim of this study is to provide more insight in the thermal environment of occupants in real life situations and to explain differences in energy use by these differences in individual thermoregulatory behaviour in similar dwellings using measured fysiological parameters and a biophysical model.

\subsection{The thermoneutral zone model}

The TNZ model includes physiological differences between occupants. From a biological point of view the body wants to use as little energy as possible to ensure its core temperature, which is shown in Fig. 1.

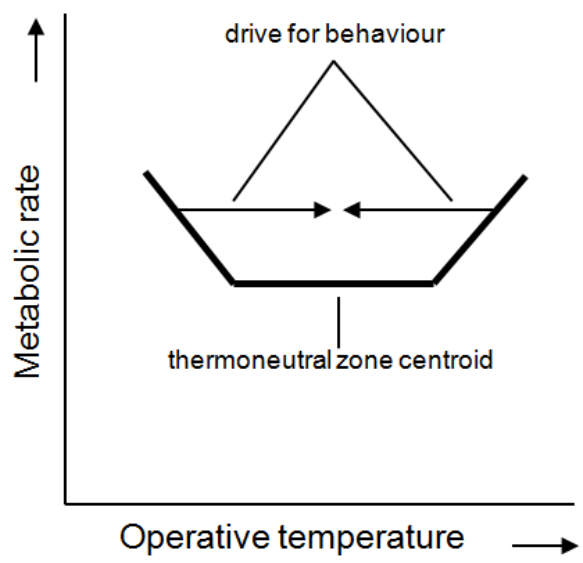

Fig. 1. Schematic view of the thermoneutral zone where the body is able to maintain body temperature without regulatory increases in metabolic rate or sweating. The distance to the center of the thermoneutral zone is hypothesized as a driving factor for thermal behaviour.
The core temperature of a body is very stable and around 37 degrees Celsius. The area in which the body is in neutral state is called the thermoneutral zone, wherein the comfort zone acts as centre. When the operative temperature increases or decreases the body has to work harder to maintain its core temperature by regulating its veins to increase or decrease the heat loss of the body. When regulating through dry heat loss is not sufficient enough, the temperature will be regulated by sweating or shivering $[8,9]$.

In addition thermoneutrality can be achieved at a range of body skin temperatures. The skin temperature can be determined by the amount of body fat and the amount of produced heat; known by the metabolism of a person $[8,9]$. As a result, the optimal operative temperature can be determined by combining the thermal resistance of the clothing with the relative humidity and the air velocity of the environment [8,9]. The influence of all these parameters can be derived from these calculations, this makes it possible to calculate the TNZ as a relation of the skin temperature and the operative temperature, see Fig. 2 $[8,9]$.

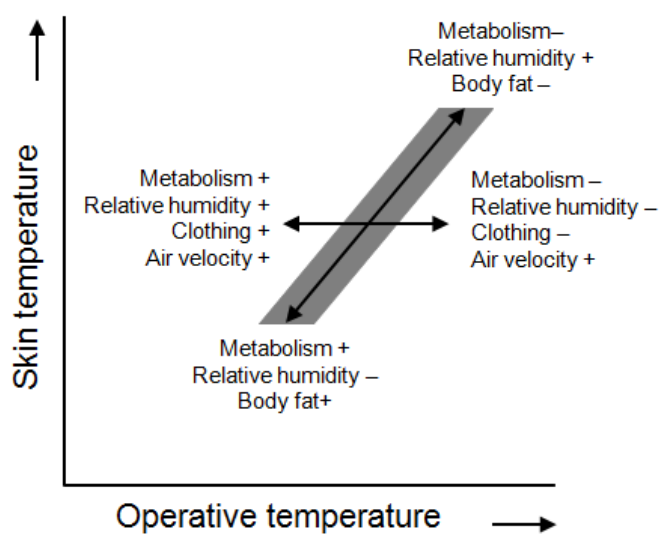

Fig. 2. The thermoneutral zone as a result of the relation between skin temperature and operative temperature $[8,9]$

As can be seen in Fig. 2, the grey zone indicates the thermoneutral zone. The position of this zone in the graph depends on the characteristics of the person, like body fat and metabolism. In addition, the position depends on the clo-value, relative humidity and air velocity $[8,9]$. Outside of this zone, the body will need to regulate its temperature more extensively trough sweating and shivering, which can be experienced as uncomfortable $[8,9]$.

The thermoneutral zone model can be used to explain differences in comfort and thermoregulatory behaviour between occupants. To use the thermoneutral zone model, the skin- and exposed temperature of the occupants need to be measured. These combinations of temperatures can then 
be used to predict the comfort level and the expectation that the occupant exhibits thermoregulatory behaviour.

\subsection{Energy consumption model}

The goal of this study is also to explain differences in energy use due to differences in thermoregulatory behaviour of occupants in similar dwellings. The hypothesis is whether a difference in comfortable indoor temperature between occupants might be the reason for variation in energy demand between similar dwellings. Therefore, real-life measurements are taken into account when calculating the energy use of the dwelling in order to include the actual differences in setpoint temperatures.

For this purpose a correlation model is developed. In equation (1), $\mathrm{Q}$ is the total heating demand for a dwelling in $\mathrm{kWh}_{\text {th. }}$ Q out $\left[\mathrm{kWh}_{\text {th }}\right]$ stands for the heat flows going out of the dwelling, e.g. ventilation, infiltration and transmission. $\mathrm{Q}_{\text {in }}\left[\mathrm{kWh}_{\mathrm{th}}\right]$ stands for the incoming heat flows by internal heat gain and solar radiation. The development of the model is based on equation (1). In addition, this model is developed because it is easy adjustable to different utilization and building characteristics, and it is possible to investigate differences in utilization of the dwelling by for example revere modelling. Furthermore, real time measurements can be used in the calculation of $\mathrm{Q}\left[\mathrm{kWh}_{\mathrm{th}}\right]$ (e.g. in- and outdoor temperatures, ventilation flow, wind speed and energy use of appliances and installations).

$$
\mathrm{Q}=\mathrm{Q}_{\text {out }}-\mathrm{Q}_{\text {in }} \quad\left[\mathrm{kWh}_{\mathrm{th}}\right]
$$

From previous research it is known that there is a strong linear correlation between the energy demand and the difference between in- and outdoor temperature $(\Delta \mathrm{T})$. This means that the energy demand will always increase when the difference between the in- and outdoor temperature increases (a higher $\Delta \mathrm{T}$ ) [12]. Fig. 3 shows this principle. The slope and the place of the line in the graph depends on different aspects and the utilization of the dwelling, such as the number of occupants, the ventilation rate, the internal heat load, the efficiency of the energy production and the amount of insulation.

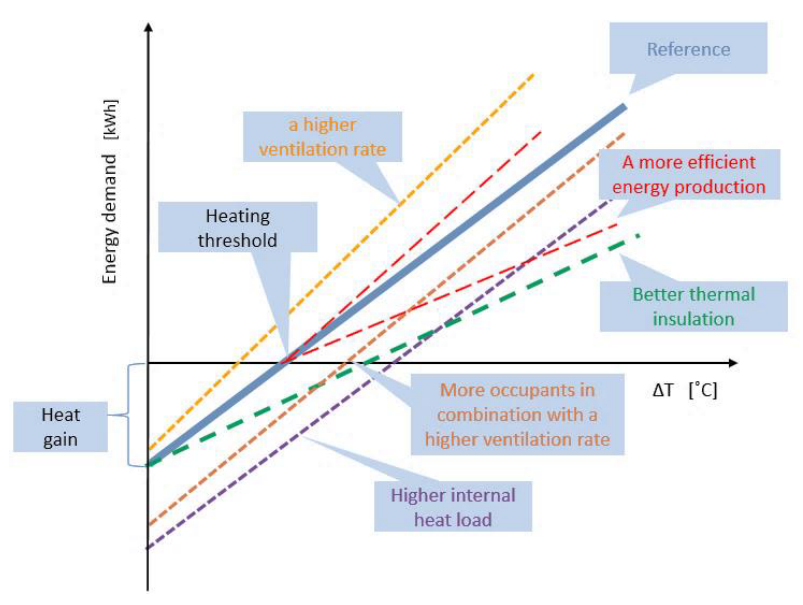

Fig. 3. Energy demand against the difference in in- and outdoor temperatures

\section{Methods}

The two female subjects (age 22 and 20) lived in a single family rowhouse which was recently renovated to a near zero energy building. There were three measuring weeks in total over a period of three months (Oct - Dec 2015). Data was collected in several ways to get more insight in the thermal environment and the behaviour of occupants in real life situations.

\subsection{Data collection}

First, general information was collected about the subject before the measurements started. The test-subjects filled in a general questionnaire, regarding illnesses and medicine use. In addition, anthropometric data was collected, e.g. age, sex, height and weight. The female test-subjects were using a birth control pill or IUD and were not measured during their menstruation period to exclude hormonal effects on thermoregulation $[13,14]$. The data was used to calculate the body metabolic rate (BMR) with the Harrison-Benedict equation [15] and the total body surface is calculated with the Dubois method [16].

Second, data was collected by energy use measurements of the house and the following parameters were measured in the house: in- and outdoortemperatures, set-point temperatures, $\mathrm{CO}_{2}$ concentrations, ventilation flows, heat flow of central heating and tapwater, electrical power use, the electrical use of installations (heatpump, boilers and ventilation).

Third, data was collected by using different sensors on the subjects bodies: skin temperature sensors (Fig. 4), an iButton as a brioche on the outer side of their clothing to measure the micro climate (exposed temperature), temperature and relative humidity (this was placed with a 
brioche at the outer layer of the clothing), and an Actiwatch ${ }^{\circledR}$ to measure their activity level.

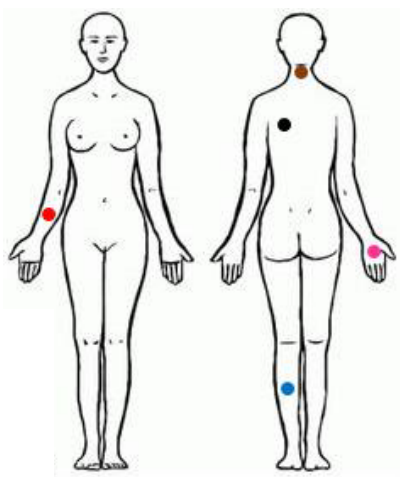

Fig. 4. Four point ISO-defined skin sites to measure skin temperatures. An extra iButton was placed at the under arm.

Fourth, data was collected by questionnaires which had to be filled in by the subjects every two hours. The questions were about: their perceived thermal comfort and sensation (7-point scale), their clothing, their activity level and thermoregulatory behaviour. The corresponding clovalues were calculated using the results from the questionnaire $[18,19]$.

\section{Results}

Most of the results presented in this paper are of one female test-subject, test-subject 1. The same analysis is conducted on the data of test-subject 2. During this study the different perceived sensation and comfort votes of the two subjects are handled separately. For both test-subjects no correlations could be found between skin temperatures and comfort or sensation vote (respectively $\mathrm{R}^{2}=0.0087, \mathrm{p}$ $=0.1947$ and $\mathrm{R}^{2}=0.0007, \mathrm{p}=0.7212$ ).

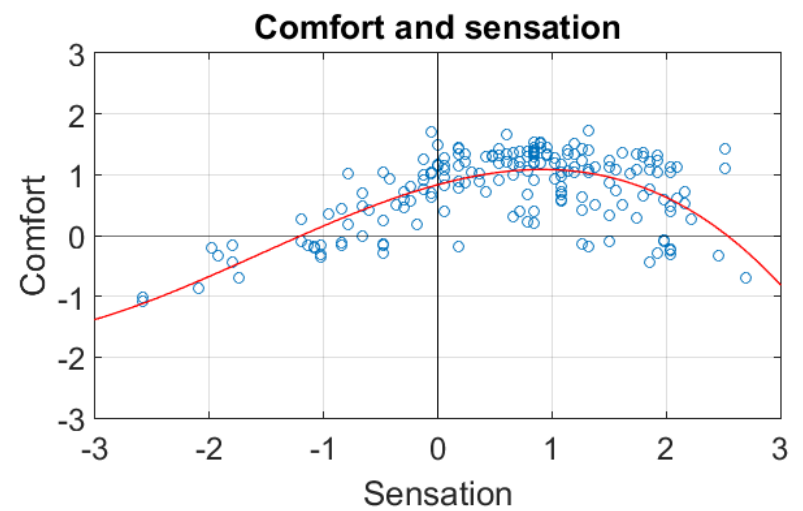

Fig. 5. Comfort vote against sensation vote of test-subject 1 for all measuring weeks

In the PMV-model of Fanger, sensation and comfort are identified as one and the same. Fig. 5 shows the comfort vote in relation to the sensation vote. A significant correlation can be found $\left(\mathrm{R}^{2}=0.5000, \mathrm{p}=0.0279\right)$. As can be derived through the trend line: the test-subject 1 is most comfortable (average comfort vote of 1 ) at a sensation vote of 1 , 'slightly warm'. test-subject 2 showed the same trend.

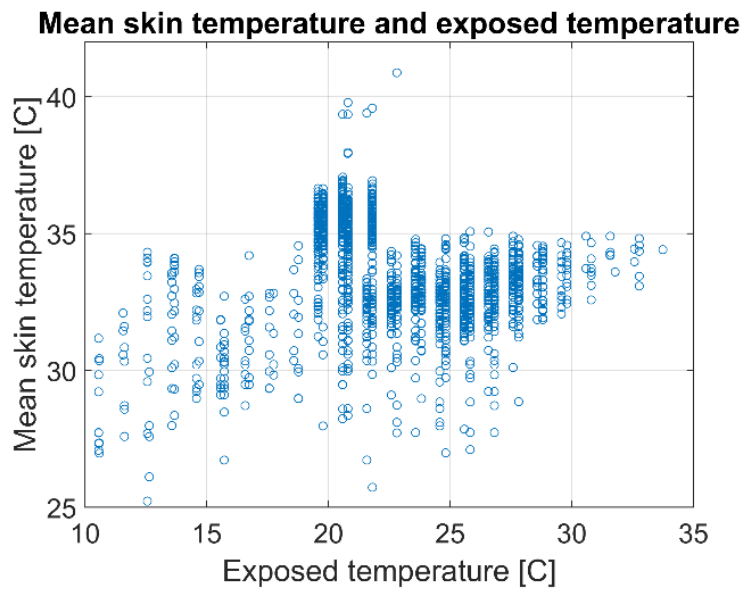

Fig. 6. Mean skin temperature against exposed temperature $\left(\mathrm{R}^{2}=0.0100, \mathrm{p}=0.1177\right)$ of test-subject 1 for all measuring weeks

Fig. 6 shows the mean skin temperature in relation to the exposed temperature, which is the ambient temperature in proximity of the subject (sensors on the outer layer of the clothes). From the more than 2000 measuring points, no real correlations can be found $\left(\mathrm{R}^{2}=0.0100, \mathrm{p}=\right.$ $0.1177)$. Although, the density of the measuring points indicate that there are skin temperature and exposed temperature combinations that occured frequently.

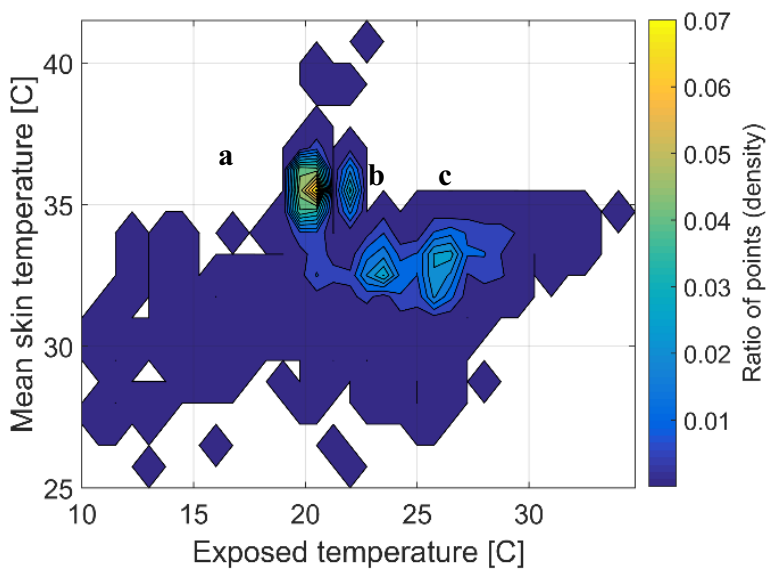

Fig. 7. Contourplot of the data in Fig. 5 with three centers $(\mathrm{a}, \mathrm{b}, \mathrm{c})$

Fig. 7 shows a contourplot of the data of test-subject 1 in Fig. 6. The contourplot shows three different hot spots $(a, b, c)$. Both test-subjects show comparable three centers at slightly different area's in the graphs. These three centers represent the thermal environment of this testsubject in real life. All three areas were associated with 
maximum comfort (score of 1 or higher in the questionnaire).

A difference in comfort and thermoregulatory behaviour is shown between the two subjects. In Fig. 8 the contour plots are shown from test-subject 2 (upper graph) and subject 1 (lower graph). The both graphs show that the measurement zones of test-subject 2 are moved to the left of the graph compared to the measurements of test-subject 1. This means that test-subject 2 is more comfortable at lower temperatures than test-subject 1 .
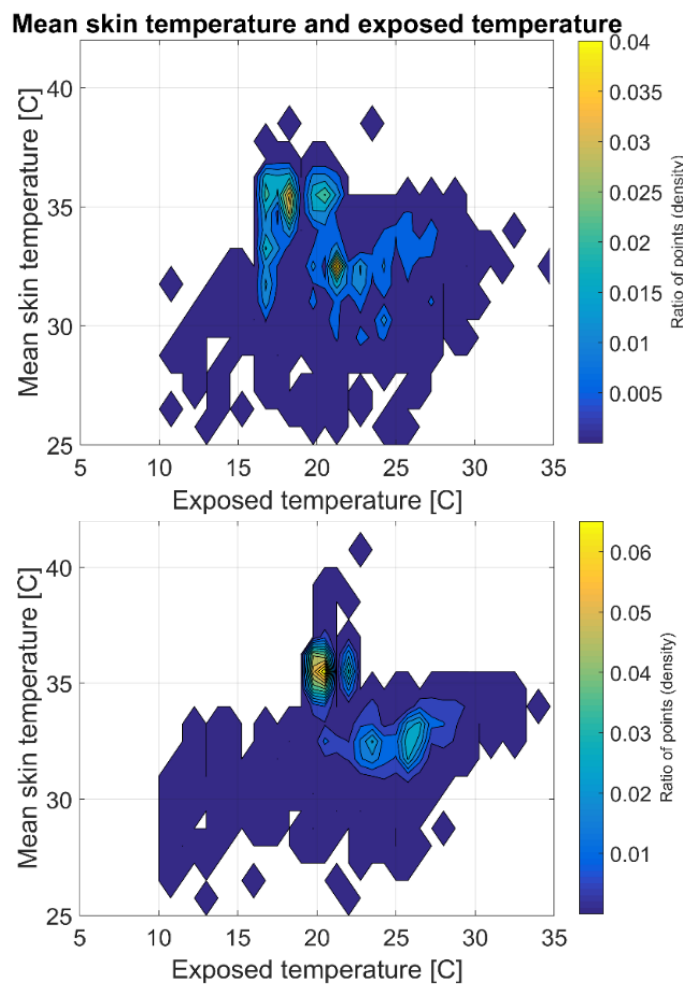

Fig. 8. Contourplot of the exposed- and skin temperatures for test-subject 2 (upper graph) and test-subject 1 (lower graph)

Combining this information with the questionnaire outcomes identifies center a. in Fig. 7 with measurements during the night. The test-subjects wore the sensors continuously (24hours/ day), which means that there are also many measuring points during the night. Center $b$. corresponds with standing activities in an indoor environment with regular winter clothing (e.g. jeans and sweater, clo-value \pm 0.8$)$. Center c. corresponds with sitting/resting activities and lower clo-values $(<0.6)$.

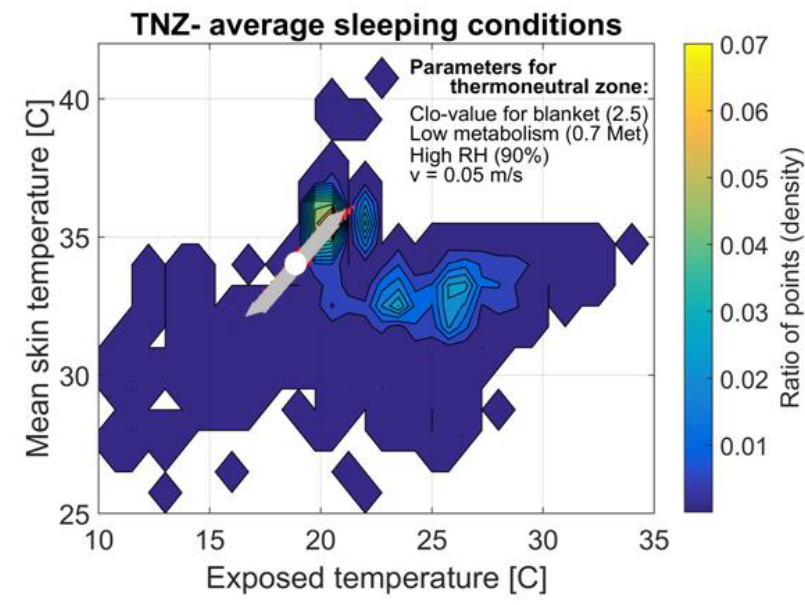

Fig. 9. Contourplot of measurements including the calculated TNZ for this test-subject 1 with parameters that should represent the micro climate in bed

Fig. 9 shows the thermoneutral zone with the characteristics for test-subject 1 with parameters that should represents the micro climate in bed, e.g. a low air velocity, a high relative humidity, a low metabolism and a high clo-value for the blanket. As can be seen in the Figure, this calculated TNZ corresponds with the measured data (hot spot "a").

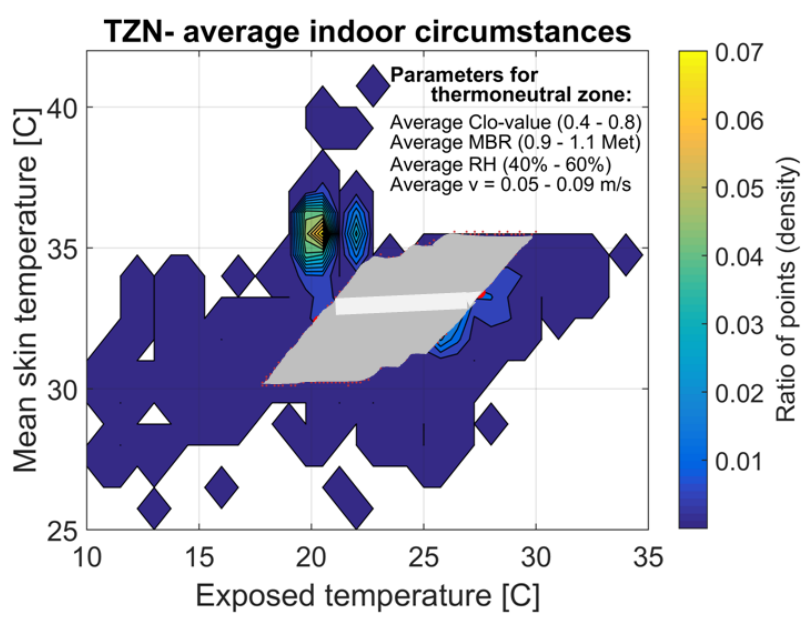

Fig. 10. Contourplot of measurements including a range of calculated TNZ's for test-subject 1 with parameters that should represent the indoor environment

Fig. 10 shows a range of calculated thermoneutral zones with the characteristics for this test-subject with parameters that should represents deviations for a normal indoor climate during the day. A range of TNZ's is calculated because the relative humidity, air velocity and metabolism can change every hour. As can be seen in Fig. 10 , the calculated thermoneutral zones correspond with the measured data. 
In addition, as a more detailed example, we describe two examples in more detail. A short summary of December $13^{\text {th }} 2015$ can be found in Table 1 .

Table 1. Schedule of Sunday December $13^{\text {th }}$ ' 15 of test-subject 1

\begin{tabular}{|l|l|}
\hline Time & Action \\
\hline 10:45:00 & Getting out of bed \\
\hline 12:30:00 & Going to the grocery store \\
\hline 13:30:00 & Back home \\
\hline 18:15:00 & Going for a run \\
\hline 18:55:00 & Back home \\
\hline 20:25:00 & Taking a shower \\
\hline 22:45:00 & Going to sleep \\
\hline
\end{tabular}

Fig. 11 shows the first measuring point of December $13^{\text {th }} 2015$ of test-subject 1 , at 10:37 hour. She is still in bed, according to her schedule. Relative humidity was $56 \%$, the exposed temperature $17.6^{\circ} \mathrm{C}$, and the weighted average skin temperature $35.2^{\circ} \mathrm{C}$. According to her entries in the questionnaire, the Clo-value was 0.48 , and the corresponding metabolic rate and air velocity were $0.9 \mathrm{Met}$ and $0.05 \mathrm{~m} / \mathrm{s}$ respectively. She entered a sensation vote of 1.8 and a comfort vote of 1.07 , so she feels warm and this is just comfortable.

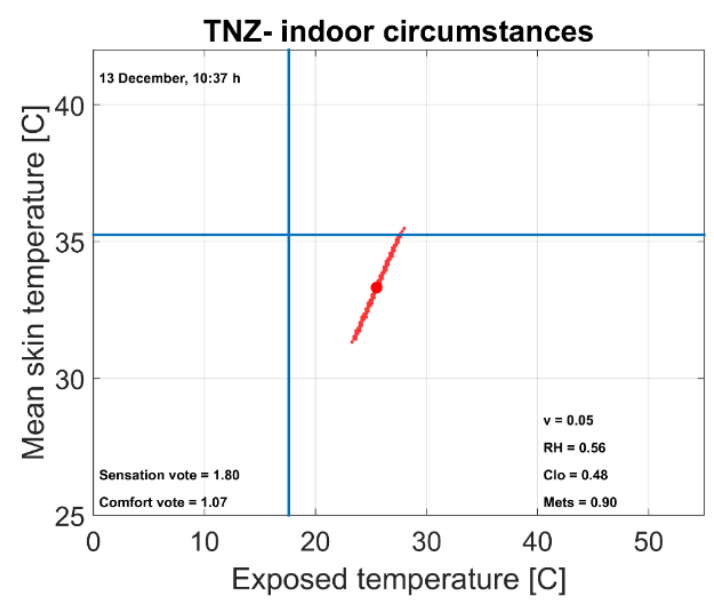

Fig. 11. Thermoneutral zone (in red) and comfort zone (red dot) calculated for measuring point $13^{\text {th }}$ December $10.37 \mathrm{~h}$ for testsubject 1 , including the measured weighted mean skin temperature (blue horizontal line) and measured exposed temperature (blue vertical line)

The body can only regulate its temperature in the surrounding environment by regulating its heat loss by dilatation and contraction of blood vessels, which increases or decreases the skin temperature. Therefore, a higher skin temperature suggests that the test-subject feels warm and a lower skin temperature suggests that the test-subject feels cold [8,9]. In Fig. 11 the skin temperature of test-subject 1 is within the higher end of the calculated thermoneutral zone. This corresponds with her sensation and corresponding comfort vote. The exposed temperature is lower than the TNZ. This indicates that the person is not in heat balance: more heat is lost and consequently she would probably start feeling colder if she does not change her environment, her clothing or her activity level.

A quarter of an hour later she is out of bed, according to her schedule. Fig. 12 shows this measuring point. Her environment, clothing and activity level are not changed after the last measuring point. Although, her sensation and comfort vote did change. She feels slightly cool, although close to neutral and this is just comfortable (sensation vote $=-0.06$, comfort vote $=1.20$ ). Her weighted average skin temperature has decreased to $33.5^{\circ} \mathrm{C}$. The exposed temperature is still lower than the thermoneutral zone. Her body responded to the relative cold exposed temperature; blood vessels are contracted, which resulted in a lower skin temperature. In addition, her sensation and comfort vote changed negatively although she still feels neutral. The body is still adapting to the colder exposed temperature, the person is still not in heat balance, more heat is lost. Most likely, she would start feeling colder if she would not change her environment, her clothing or her activity level.

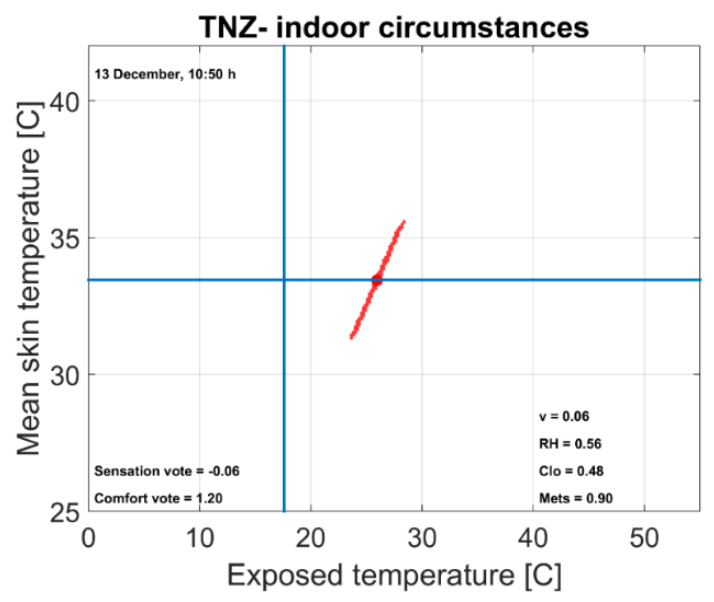

Fig. 12. Thermoneutral zone (in red) and comfort zone (red dot) calculated for measuring point $13^{\text {th }}$ December $10.50 \mathrm{~h}$ for testsubject 1 , including the measured weighted mean skin temperature (blue horizontal line) and measured exposed temperature (blue vertical line)

\subsection{Optimal indoor temperatures}

The comfort zone is likely situated around the center of the thermoneutral zone, the corresponding operative temperature is the most comfortable (optimal) indoor temperature for that person at that moment $\left(\mathrm{T}_{\mathrm{opt}}\right)[8,9]$. Because parameters such as relative humidity, air velocity, activity level and clothing can vary over time this will lead 
to a different comfort zone and thus a different optimal indoor temperature. The thermoneutral zone is calculated from the 57 questionnaire entries of test-subject 1. For all these moments a $\mathrm{T}_{\text {opt }}$ is calculated. This calculation is a steady state calculation, and the human body adapts to the exposed temperature with a slight delay over time. However, the average $\mathrm{T}_{\text {opt }}$ per test-subject can give an insight in the differences in prefered indoor temperatures. For each test-subject the $\mathrm{T}_{\text {opt }}$ per questionnaire entry was calculated for one week. Per day the average optimal temperature $\left(\mathrm{T}_{\mathrm{opt}}\right)$ was calculated to compare the differences in thermal comfort between the two testsubjects, see

Table 2.

Table 2. Average calculated $\mathrm{T}_{\mathrm{opt}}$ per day

\begin{tabular}{|l|l|l|}
\hline Date & Test-subject 1 & Test-subject 2 \\
\hline 10-nov-2016 & $25.48{ }^{\circ} \mathrm{C}$ & $19.42{ }^{\circ} \mathrm{C}$ \\
\hline 11-nov-2016 & $28.16{ }^{\circ} \mathrm{C}$ & $19.45{ }^{\circ} \mathrm{C}$ \\
\hline 12-nov-2016 & $24.73{ }^{\circ} \mathrm{C}$ & $20.20{ }^{\circ} \mathrm{C}$ \\
\hline 13-nov-2016 & $24.04{ }^{\circ} \mathrm{C}$ & $20.20{ }^{\circ} \mathrm{C}$ \\
\hline 14 -nov-2016 & $24.28{ }^{\circ} \mathrm{C}$ & $20.73{ }^{\circ} \mathrm{C}$ \\
\hline 15-nov-2016 & $25.69{ }^{\circ} \mathrm{C}$ & $24.61{ }^{\circ} \mathrm{C}$ \\
\hline 16-nov-2016 & $25.84{ }^{\circ} \mathrm{C}$ & $18.99{ }^{\circ} \mathrm{C}$ \\
\hline
\end{tabular}

\section{Discussion}

The calculation of $\mathrm{T}_{\mathrm{opt}}$ is a steady state calculation, and the human body adapts to the exposed temperature with a slight delay over time, because the calculation is depended on the physiology of a person (e.g. gender, weight, height, amount of body fat and metabolism) and his or her clothing. A person with little body fat is more sensitive to variations in ambient temperatures, because of the lack of thermal resistance. Consequently, a person with more body fat is less sensitive to deviations in ambient temperatures. Furthermore, a taller person has a higher body surface, so will easier be cold. All these parameters will have an influence on the speed at which the body responds to changes in exposed temperatures.

Both test-subjects are female and approximately the same age, height and weight. Although their calculated optimal temperatures differ. From the questtionaire inputs is is known that test-subject 1 changed to relax wear after returning from school (lower Clo value), in addition testsubject 2 was more active in the household (higher metabolism). These differences may explain the differences in the optimal calculated temperatures for both test-subjects.

However, it is not always possible to change the temperature set-points for example in office buildings or when multiple people are living in the same dwelling, with all different comfort levels. As an addition to changing setpoint temperatures, people can reduce their sensitivity for variations in temperatures by changing the worn clothing. More clothing, a higher clo-value, will result in a shift of the TNZ to a lower ambient temperature. Less clothing will result in the oposite. This is probably why two almost optically similar women, can have a differentiation between their calculated optimal temperatures, while adapting to eachother because they live together.

By combining the energy measurement of the dwelling together with the calculated optimal temperatures of both test-subjects and the measured temperature setpoint, it is possible to calculate the dwellings energy expenditure, using the earlier presented correlation model (Fig. 13). The graph shows the result of one day where both test-subject 1 and 2 were measured.
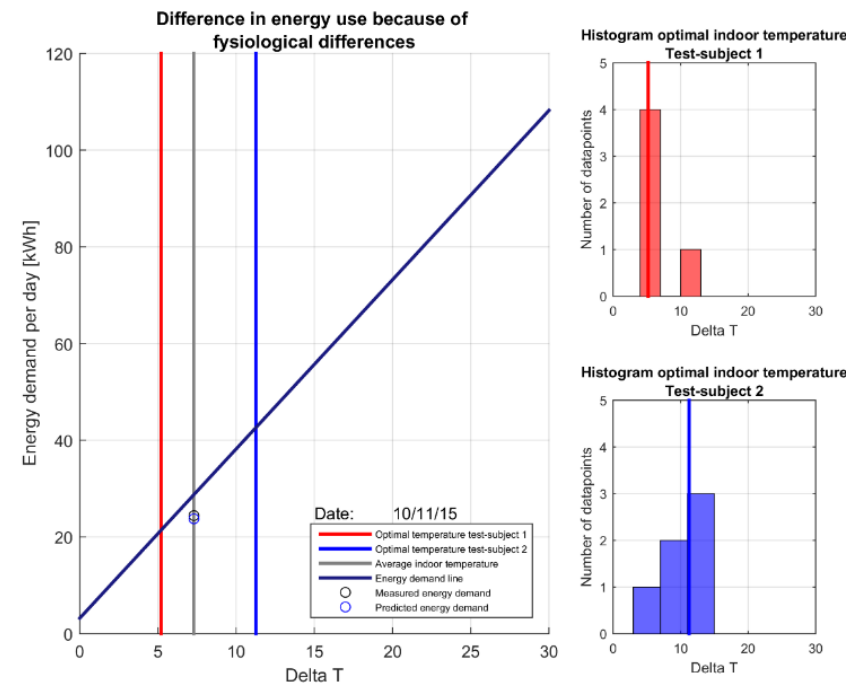

Fig. 13. Differences in energy use because of physiological differences $-10^{\text {th }}$ of November 2015. Including the calculated average $\Delta \mathrm{T}_{\text {opt }}$ for test-subject 2 (red) and 1 (blue), the measured $\Delta \mathrm{T}$ of the living room (grey), the energy demand line depending on the amount of infiltration (dark blue) and the measured (black dot) and calculated (blue dot) energy demand

For each test-subject the optimal temperature $\left(\mathrm{T}_{\mathrm{opt}}\right)$ per questionnaire entry was calculated. Per day the average optimal temperature $\left(\mathrm{T}_{\text {opt }}\right)$ was calculated and substracted by the outdoor temperature of that day $(\Delta T)$, to exclude the influence of the weather. On the right the histograms per day and per test-subject of all the calculated optimal temperatures (substracted by the outdoor temperature) are shown. On the left again the average calculated $\mathrm{T}_{\text {opt }}$ are shown for test-subject 1 and 2 (red and blue line). The grey line corresponds with the average indoor livingroom temperature of that day, subtracted by the corresponding 
outdoor temperature. The dark blue line is the energy demand line corresponding with the $\mathrm{Q}_{\text {measured }}$ of that day. In other words, the red line corresponds with the average optimal indoor temperature for test-subject 2 of that day and the blue line corresponds with the average optimal temperature for test-subject 1 of that day. The grey line indicates the real indoor temperature of that day. It is not sure if the test-subjects would act on their optimal indoor temperature if they would live alone, but it could be that test-subject 2 would set a lower indoor temperature as a set-point compared to the setpoint that she agreed on with test-subject 1 . This applies vice versa, i.e. test-subject 1 would set a higher indoor temperature as a set-point compared to the setpoint that she agreed on with testsubject 2. Except for the $15^{\text {th }}$ of November, test-subject 1 would always prefer on average a lower indoor temperature compared to test-subject 1 . The agreed indoor temperature set-point is except for the $15^{\text {th }}$ of November, always in the middle of the average optimal indoor temperatures of both test-subjects.

\section{Conclusion}

From the results it can be concluded that the gap between measured and calculated energy use will probably not completely be explained by using the TNZ model. Nevertheless, this model can explain differences in individual indoor temperature preferences which might contribute for a (large) part to the gap.

This study highlights the differences in individual thermoregulatory behaviour, comfort and resulting optimal indoor temperatures. When the average calculated optimal temperatures are being compared, differences in optimal indoor temperatures can be distinguished. From these calculations, the following conclusions can be drawn: testsubject 2 is more comfortable at lower temperatures compared to test-subject 1 . the set-point temperature of the living room was in the middle of these calculated optimal temperatures as was seen in the measurements. This example shows that the energy use can differ a factor 2 between individuals when the average optimal indoor temperatures of serve as input in the model..

Both test-subjects are female and approximately the same age, height and weight. Several studies suggest that there might be great differences in comfort between men and women, lean and obese and young and elderly. This study shows also that there are also significant differences between two almost similar females and that the energy demand might vary up to a factor 2 . In addition, the differences between subpopulations might be even greater. This might explain why in some projects the highest measured energy consumption is a factor 5 higher than the lowest measured energy consumption [21, 22].

\section{References}

1. Tohoku University. (2013). Annex 53 Total energy use in buildings. Sendai, Japan: International Energy Agency.

2. Guerra-Santin, O., Boess, S., Konstantinou, T., Klein, T., \& Silverster, S. (2016). Renovation of social housing in the Netherlands.

3. C. Jacquot, L. Schellen, B. Kingma, M. van Baak, \& W. van Marken Lichtenbelt (2013). Influence of thermophysiology on thermal behaviour: the essentials of categorization. Maastricht: Department of human biology Maastricht University.

4. P. Fanger (1973). Assesment of man's thermal comfort. Lyngby: British Journal of Industrial medicine.

5. G.S. Brager, \& R. de Dear (2000). A standard for natural ventilation, (October).

6. J.F. Nicol, \& M.A. Humphreys (2002). Adaptive thermal comfort and sustainable thermal standards for buildings, 34, 563-572.

7. S. Karjalainen (2011). Thermal comfort and gender: a literature review. Helsinki, Finland.

8. B. Kingma, A. Frijns, L. Schellen, \& W. van Marken Lichtenbelt (2014). Beyond the classic thermoneutral zone, including thermal comfort, July/ August/

September. Maastricht: Temperature 1:2.

9. B. Kingma, \& W.D. van Marken Lichtenbelt (2015). Energy consumption in buildings and female thermal demand, August. Maastricht: Nature Climate Change.

10. IUPS Thermal Commission. (2001). Glossary of terms for thermal physiology, Third Edition. k.n.: The Japanese Journal of Physiology.

11. ASHRAE. (2004). Thermal Environmental Conditions for. Atlanta: $A S H R A E$.

12. TRECO-home (2018). Retrieved from http://www.tki-treco.nl/

13. F. Baker, D. Mitchell, \& H. Driver (2001). Oral contraceptives alter sleep and raise body temperaure in young women. k.n.: k.n.

14. F. Baker, J. Waner, E. Vieira, S. Taylor, H. Driver, \& D. Mitchell (2001). Sleep and 24 hour body temperatures: a comparison in young men, naturally cycling women and women taking hormonal contraceptives. k.n.: k.n.

15. J. Harris, \& F. Benedict (1918). A biometric study of human basal metabolism. Washington: Carnegie institution of Washington.

16. D. Dubois, \& E. Dubois (1916). A formula to estimate the approximate surface area if height and weight be known. n.k.: Arch Intern Med.

17. D. Wang, H. Zhang, E. Arens, \& C. Huizenga (2006). Observations of upper-extremity skin temperature and corresponding overall-body thermal sensations and comfort. Berkeley: University of California. 
18. E. McCullough, B. Jones, \& J. Huck (1985). A Comprehensive Data Base for Estimating Clothing Insulation. Atlanta: $A S H R A E$.

19. E. McCullough, B. Jones, \& T. Tamura (1989). A data base for determining the evaporative resistance of clothing. Atlanta: ASHRAE.

20. M. Schweiker, B.R.M. Kingma, \& A. Wagner (2017). evaluating the performance of thermal sensation prediction with a biophysical model. Indoor Air, 49(0), 0-3. http://doi.org/10.1111/ijlh.12426

21. A. Borg (2015). Alexander Borg and Calculated Energy Demand Relationships Between Measured in the Norwegian Dwelling Stock.

22. T. Steen, N. Henrik, A. Marie, E. Tove, P. Kvols, T.S. Larsen, J. Rose (2010). Occupants influence on the energy consumption of Danish domestic buildings - State of the art. 